\title{
Impactos do eSocial na construção civil e reflexos na segurança do trabalho
}

A construção é um setor de grande representação econômica para o país, em virtude da geração de emprego e renda. Apesar da sua importância, é um setor que apresenta altos riscos de acidente no trabalho, sendo considerado um dos setores de maiores índices de acidente e morte no trabalho no país. Nesse sentido, o governo vem implantando novas técnicas para fiscalização e facilitação da regularização de empresas, inclusive de obras da construção civil, entre elas encontrase o eSocial. Criado em 2014, o objetivo do eSocial é facilitar a administração de informações relativas aos trabalhadores, unificando e padronizando a execução de 15 obrigações fiscais, previdenciárias e trabalhistas. Dentre as obrigações trabalhistas, verifica-se a presença de documentos relativos à Saúde e Segurança no Trabalho, que devem ser regularizados pelos empregadores junto ao governo federal. Frente ao exposto, buscou-se investigar os impactos do eSocial na construção civil e seus reflexos na segurança do trabalho. Identificou-se que o eSocial é altera significativa e positivamente a rotina dos profissionais de segurança e saúde ocupacional, bem como a indústria da construção civil, visto que ele não só altera a legislação da área, como também é uma forma de verificar a prática destas legislações nas empresas. Apesar disso, muitos empregadores vem criticando o sistema, em virtude da ampla obrigatoriedade de apresentação de documentos, 0 que burocratiza a execução dos serviços nas empresas, o que fez com que o governo federal anunciasse a extinção do eSocial por um sistema mais simples, onde no que se refere à Saúde e Segurança no Trabalho, o novo sistema contemplará somente a obrigação quanto ao Comunidade de Acidente no Trabalho, podendo ser um impasse para a fiscalização do ambiente da construção civil.

Palavras-chave: eSocial; Segurança do Trabalho; Construção Civil.

\section{Impacts of eSocial on civil construction and reflexes on work safety}

Construction is a sector of great economic representation for the country, due to the generation of jobs and income. Despite its importance, it is a sector that presents high risks of accident at work, being considered one of the sectors with the highest rates of accident and death at work in the country. In this sense, the government has been implementing new techniques to inspect and facilitate the regularization of companies, including civil works, including eSocial. Created in 2014, the purpose of eSocial is to facilitate the administration of information related to workers, unifying and standardizing the execution of 15 tax, social security and labor obligations. Among the labor obligations, there is the presence of documents related to Health and Safety at Work, which must be regularized by employers with the federal government. Based on the above, we sought to investigate the impacts of eSocial on civil construction and its effects on work safety. It was found that eSocial is significantly and positively changes the routine of occupational safety and health professionals, as well as the construction industry, as it not only changes the legislation of the area, but is also a way to verify their practice. legislation in business. Despite this, many employers have been criticizing the system, due to the wide obligation to submit documents, which bureaucratizes the execution of services in companies, which led the federal government to announce the extinction of eSocial by a simpler system, where With regard to Occupational Health and Safety, the new system will only include the obligation regarding the Occupational Accident Community, which may be a deadlock for the supervision of the construction environment.

Keywords: eSocial; Workplace safety; Construction.

\section{Topic: Engenharia Civil}

Reviewed anonymously in the process of blind peer.
Received: 12/05/2019

Approved: 24/08/2019
Cynthia Carita Luciano da Silva Brito Cynthiacarita Instituto Tocantinense Presidente Antônio Carlos, Brasil http://lattes.cnpq.br/9131456480882612

cynthiacarita16@gmail.com

Fernando Antônio da Silva Fernandes (i

Instituto Tocantinense Presidente Antônio Carlos, Brasil

http://lattes.cnpq.br/32849755774884687

http://orcid.org/0000-0003-4718-3230

fernando.fernandes@itpacporto.edu.br
Referencing this:

CYNTHIACARITA, C. L. S. B.; FERNANDES, F. A. S.. Impactos do eSocial na construção civil e reflexos na segurança do trabalho. Technology Science, v.1, n.2, p.15-23, 2019. DOI:

http://doi.org/10.6008/CBPC2674-6425.2019.002.0003

DOI: 10.6008/CBPC2674-6425.2019.002.0003

${ }^{\circledR}$ Companhia Brasileira de Produção Científica. All rights reserved. 


\section{INTRODUÇÃO}

A construção civil é um ramo industrial muito importante para a economia do Brasil, verificada a partir do envolvimento de uma grande cadeia produtiva, geração de emprego e renda, o que por consequência movimenta a economia do país (MORAES, 2017). Por esse motivo, quando o setor está em baixa indica que o estado econômico do Brasil está com algum problema. Este fenômeno ocorre porque a construção civil utiliza uma enorme quantidade de mão de obra e consome muitos recursos e serviços indiretamente relacionados.

Associada a essa grande absorção da mão de obra e as condições de riscos presentes na indústria da construção surge muitos problemas relacionados às condições de trabalho do setor. O primeiro ponto é que a maioria dos trabalhadores estão trabalhando de forma informal, e isso geralmente gera ônus de direitos trabalhistas, seja por falta de informação ou por medo de sofrer represálias no ambiente de trabalho.

No Brasil existem leis e normas que tratam sobre a Segurança e Saúde do Trabalho (SST), destacandose, principalmente as Normas Regulamentadoras (NRs), que dispõem de diversas normativas que vão desde a seleção dos equipamentos de proteção individual (EPI), até a elaboração de programas de proteção e saúde no trabalho a ser implantado nos empreendimentos.

Moterle (2014) afirma que o objetivo principal da Saúde e Segurança no Trabalho (SST) é a prevenção de acidentes, aliada à preservação da integridade física do trabalhador, isso porque os acidentes causam danos como diminuição da produtividade, perdas de materiais, gastos acima dos esperados, entre outros. Para que uma obra da construção civil tenha sucesso em todos os âmbitos, a empresa deve cumprir e exigir os requisitos mínimos de segurança e saúde no trabalho, estabelecidos através das Normas Regulamentadoras, para prevenir os acidentes e/ou doenças em decorrência do trabalho (SILVA et al., 2015).

Em virtude das necessidades relacionada à SST, o governo federal deve realizar fiscalização na construção civil, de modo a diminuir a negligência. Nesse sentido, aliado à necessidade de haver uma regularização quanto as obrigações fiscais, tributárias e trabalhistas, o governo federal vem implantando novas ferramentas que tem por finalidade aumentar o poder de fiscalização em seguimentos relacionados ao trabalho. Sendo o eSocial um dos projetos mais ousados e complexo a serem implantados. O eSocial é definido como um sistema de registro para facilitar a administração de informações relativas aos trabalhadores, unificando e padronizando a execução de 15 obrigações fiscais, previdenciárias e trabalhistas (BRASIL, 2017).

As principais vantagens da implantação do eSocial é a possibilidade de alimentar um único banco de dados evitando possíveis gargalos de regularização dos empreendimentos. No ramo da construção civil espera-se que esse projeto possibilite a rápida identificação de incoerências nos sistemas de SST nos canteiros de obras. O eSocial possibilitará também a rápida Comunicação de Acidentes de Trabalho (CAT) (DONZELLI et al., 2013).

Mesmo com todas as vantagens que eSocial pode trazer ao ramo da construção civil principalmente do ponto de vista da SST, as construtoras encontraram grande dificuldades na alimentação desses dados na 
plataforma, pois para o cadastro inicial é necessária uma grande quantidade de informações detalhadas sobre a empresa, o empreendimento e os trabalhadores.

Nesse sentido, a presente pesquisa buscou realizar uma investigação quanto os reflexos que o eSocial possui na construção civil, especialmente relacionado à Saúde e Segurança no Trabalho, visto que essa associação é pouco encontrada ao se pesquisa, e é extremamente necessária, principalmente após o anúncio de substituição do eSocial por um sistema mais simples, com menos obrigações relacionadas à SST.

\section{METODOLOGIA}

A pesquisa é definida como do tipo descritiva, exploratória, com abordagem qualitativa, através de uma pesquisa bibliográfica. A pesquisa descritiva visa descrever, analisar e verificar a relação entre fatos e fenômenos existentes na pesquisa, realizando investigações detalhadas para um melhor entendimento quanto as causas e consequências daquilo que é pesquisada (PRODANOV et al., 2013).

Segundo Duarte et al. (2009), as pesquisas exploratórias desenvolvem, esclarecem e modificam conceitos e ideias para a formulação mais precisa dos problemas e as pesquisas descritivas são aquelas que visam descrever as características da população ou fenômenos pesquisados e estabelecer as relações entre as variáveis.

No que se refere à abordagem, a pesquisa com o método qualitativo busca a descrição da relação entre os objetivos e resultados por meio de interpretações descritivas, sem utilização de representatividade numérica (PRAÇA, 2015). Para a obtenção dos dados da pesquisa, utilizou-se o meio bibliográfico como a fonte direta dos mesmos. Segundo Prodanov et al. (2013), a pesquisa bibliográfica é aquela desenvolvida a partir de materiais já existentes, como livros e artigos, permitindo uma ampla variedade de fenômenos a serem pesquisados.

Frente ao exposto, realizou-se uma pesquisa bibliográfica para a obtenção dos dados necessários à realização da pesquisa, através principalmente de artigos afins, bem como revistas, dados de sites e outros meios pertinentes no ambiente virtual. Em virtude de a pesquisa se referir ao eSocial, um sistema criado em 2014, a grande maioria da bibliografia utilizada data a partir desse ano. Porém também houve uma verificação em artigos com datas anteriores.

Como o trabalho não se trata de uma pesquisa com pessoas, apenas uma análise do caso por meio de materiais já publicados, não havendo, portanto, intervenção ou abordagem direta junto à seres humanos, não houve à necessidade de submissão ao Comitê de Ética em Pesquisa, conforme a resolução 466/2012. Por se tratar de uma pesquisa relacionada ao eSocial associado à construção civil, identificou-se que em virtude de ser um tema relativamente novo, não há uma variedade de bibliografia relacionada à associação, por esse modo, há uma forte presença de opiniões e verificações da autora para associar a influência do eSocial na construção civil.

\section{RESULTADOS E DISCUSSÃO}

A partir da investigação realizada quanto as atividades que a empresa do setor da construção civil 
deve realizar para se adequar ao eSocial, identificou-se que há informações pouco detalhadas sobre, visto que este é um sistema recente, criado somente em 2014. Nesse sentido, ao associar o eSocial à construção civil, os resultados se referem a perspectivas da própria autora. O eSocial pode ser definido como "a escrituração da Folha de Pagamento, Segurança do Trabalho, Medicina Ocupacional e Informações Fiscais relacionadas a contratação de mão de obra onerosa" (VIANA et al., 2014).

Segundo Brasil (2017), o eSocial é um sistema de informação que unifica de forma 15 obrigações que os empregadores e empresas devem se adequar, são elas: GFIP - Guia de Recolhimento do FGTS e de Informações à Previdência Social; CAGED - Cadastro Geral de Empregados e Desempregados para controlar as admissões e demissões de empregados sob o regime da CLT; RAIS - Relação Anual de Informações Sociais; LRE - Livro de Registro de Empregados; CAT - Comunicação de Acidente de Trabalho; CD - Comunicação de Dispensa; CTPS - Carteira de Trabalho e Previdência Social; PPP - Perfil Profissiográfico Previdenciário; DIRF - Declaração do Imposto de Renda Retido na Fonte; DCTF - Declaração de Débitos e Créditos Tributários Federais; QHT - Quadro de Horário de Trabalho; MANAD - Manual Normativo de Arquivos Digitais; Folha de pagamento; GRF - Guia de Recolhimento do FGTS; GPS - Guia da Previdência Social.

Segundo Brasil (2018), o eSocial foi implantado em fases, onde as obrigações foram gradativas e ainda não foram finalizadas, conforme a figura 1. Porém não há realmente uma finalização da implantação dos programas e obrigações, visto que há mudanças constantemente, entre elas a última mudança anunciada, sendo a mudança do eSocial para outros dois sistemas mais simples.

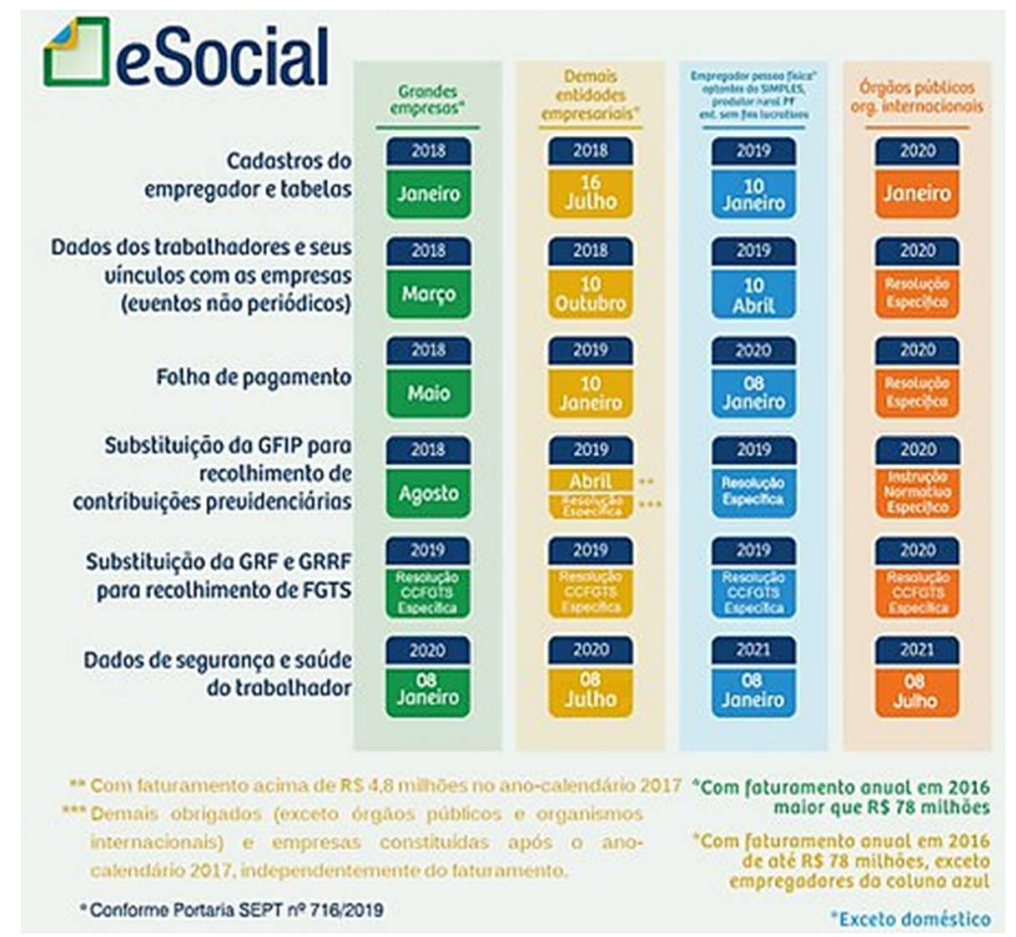

Figura 1: Cronograma de implantação do eSocial. Fonte: Brasil (2018).

No que se refere às obrigações existentes no eSocial relacionadas à Saúde e Segurança no Trabalho (SST), identifica-se que há duas associadas, sendo: Comunicado de Acidente no Trabalho (CAT) e Perfil Profissiográfico Previdenciário (PPP). Entretanto, de acordo com Ocupacional (2019), além dessas obrigações, há seis documentos que devem ser entregues ao eSocial para uma regularidade quanto à Saúde 
e Segurança no Trabalho, são eles: Programa de Controle Médico de Saúde Ocupacional (PCMSO) - Esse programa especifica procedimentos e condutas a serem implantados pela empresa para garantir a Saúde e Segurança no Trabalho. É determinado pela NR 7, desde 1978, e está relacionada principalmente à realização de exames para a garantir da saúde e segurança do trabalhador; Laudo de Periculosidade - A periculosidade é qualquer exposição a agentes que possam causar a morte do trabalhador. O laudo deve ser elaborado apontando os riscos e deve ser atualizado anualmente ou sempre que houver modificação no ambiente de trabalho por um médico do trabalho ou um engenheiro de segurança no trabalho; Análise Ergonômica do Trabalho (AET) -É um documento que avalia as condições necessárias ao ambiente de trabalho relacionadas às questões ergonômicas. É determinada pela NR 17, onde, segundo Brasil (2018), essa NR determina que, devem haver condições de trabalho que proporcione o máximo de conforto, segurança e desempenho eficiente possível aos trabalhadores, relacionado as características psicofisiológicas. Essa norma determina a adaptação do trabalhador ao seu serviço, como em situações de levantamento, transporte e descarga de materiais manualmente, trabalhos sentados ou em pé, além da definição do tempo de serviço, iluminação, níveis de ruído, temperatura, e todas as características para manter o conforto, saúde e segurança do trabalhador; Laudo Técnico das Condições Ambientais do Trabalho (LTCAT) - É um documento que apresenta os agentes nocivos e os riscos que geram insalubridade ao trabalhador exposto, obrigado pela Lei no 9.732/1998. Pode ser realizado pelo médico ou engenheiro de segurança no trabalho; Programa de Prevenção de Riscos Ambientais (PPRA) - É um programa determinado pela NR 9, que analisa os riscos a que os trabalhadores estão expostos no ambiente de trabalho. Segundo Brasil (2017), é de obrigação por parte dos empregadores e empresas a elaboração e implementação do Programa de Prevenção de Riscos Ambientais - PPRA, com o objetivo de preservar a saúde e integridade dos trabalhadores, através da análise dos riscos ambientais com antecipação, reconhecimento, avaliação e controle da ocorrência dos mesmos, levando em consideração a proteção do meio ambiente e dos recursos naturais; Laudo de Insalubridade - A insalubridade é o risco que o trabalhador possui ao ser exposto a agentes nocivos à sua saúde. O laudo apresenta esse risco e pode ser realizado pelo médico ou engenheiro de segurança no trabalho.

Identifica-se, portanto, que a última fase do eSocial é voltada diretamente à Saúde e Segurança no Trabalho. Segundo o Manual de Orientação do eSocial (2018) as empresas terão que enviar ao eSocial informações referentes ao monitoramento da saúde do trabalhador e das condições ambientais do trabalho - fatores de risco, portanto informações que até então podiam ser mantidas em papel e que só eram verificados em caso de fiscalização ou processo trabalhista, passarão a ser digitais para serem transmitidas mensalmente ao ambiente do eSocial.

De acordo com a Federação das Indústrias do Estado de São Paulo (2011) a Saúde e Segurança do Trabalho (SST) tem amparo legal no Art. 70 da Constituição Federal (BRASIL, 1988) em seu inciso XXII, que determina que a redução dos riscos do trabalho seja dever das empresas e direito dos trabalhadores. Além disso, o assunto está contido na Consolidação das Leis do Trabalho (BRASIL, 1943) em seus artigos 154 a 201, que de maneira genérica determinam o que deve ser feito para garantir a segurança e saúde dos trabalhadores. 
Esses artigos da Consolidação das Leis do Trabalho (CLT) foram regulamentados pelo Ministério do Trabalho através da Secretaria de Segurança e Saúde no Trabalho hoje denominado Departamento de Segurança e Saúde no Trabalho, pela Portaria no 3.214 (BRASIL, 1978) que criou originalmente 28 (vinte e oito) Normas Regulamentadoras - NR's, das atuais 36 (trinta e seis) vigentes.

O que define qual é a NR mais importante para uma empresa é o seu ramo de atividade, sendo que existem NRs que são específicas para um ramo de atividade e outras que são de observância por todas as empresas, das quais podem ser citadas as seguintes: NR 5 - Comissão Interna de Prevenção de Acidentes (CIPA), NR 6 - Equipamento de Proteção Individual (EPI), NR 7 - Programa de Controle Médico de Saúde Ocupacional (PCMSO), NR 9 - Programa de Prevenção de Riscos Ambientais (PPRA) e NR 17 - Ergonomia (BRASIL, 2014).

Ao observar as obrigações que as empresas devem seguir com o eSocial, associa-se à construção civil todos elas, visto que, independente do seguimento, toda empresa tem obrigações a serem cumpridas e seguidas junto ao governo federal, de modo a ficar em dias com as leis obrigações fiscais, previdenciárias e trabalhistas.

Segundo Buildin (2019), os benefícios referente a tal são significativos, entretanto há a necessidade de adequação mediante um ambiente um tanto quanto burocrático, visto que, ao todo, são 43 documentos que devem ser apresentados ao sistema, com 1.675 campos de informação, por esse modo há o cronograma de implantação, beneficiando a construção civil e outras áreas através de: Simplificação da prestação das informações referentes às obrigações fiscais, previdenciárias e trabalhistas; Substituição do preenchimento e a entrega de formulários e declarações; Racionalização do cumprimento de obrigações, eliminando a redundância nas informações prestadas pelas pessoas físicas e jurídicas; Aprimoramento da qualidade das informações das relações de trabalho, previdenciárias e tributárias; Diminuição na ocorrência de erros de cálculos na geração de guias de recolhimento do FGTS, por exemplo; Maior garantia aos trabalhadores em relação à efetivação de direitos trabalhistas e previdenciários.

Apesar dos benefícios gerais direcionados à construção civil, em virtude do cumprimento de todas as obrigações, o eSocial beneficia diretamente na Saúde e Segurança do Trabalho na indústria da construção civil. Nesse sentido, há duas obrigações que podem ser fortemente associadas à construção civil, são elas: Comunicado de Acidente no Trabalho (CAT) e Perfil Profissiográfico Previdenciário (PPP).

O Comunicado de Acidente no Trabalho (CAT) é um documento obrigatório, emitido quando houver acidente de trabalho, de trajeto ou uma doença ocupacional, mesmo que não haja afastamento das atividades (INSS, 2018). Sua inserção no eSocial obriga a empresa a realizar o comunicado pelo sistema, simplificando o acesso.

O Perfil Profissiográfico Previdenciário (PPP) trata-se de um formulário com todas as informações relacionadas ao empregado, entre elas a atividade exercida, os agentes nocivos de exposição e sua intensidade, exames médicos clínicos, entre outros, devendo ser preenchido pelas empresas onde há exposição dos trabalhadores à agentes nocivos químicos, físicos ou biológicos (BRASIL, 2014).

Essa associação se dá pelo fato de que a indústria da construção civil é responsável por inúmeros 
acidentes do trabalho, e isso é justificado pelo fato de que é um setor que expõe os funcionários a muitos fatores de riscos, como a altura, ruídos, calor e esforços repetitivos (MOTERLE, 2014). Nesse sentido, não somente as duas obrigações estão relacionadas à construção civil, como também toda a última fase do eSocial, em virtude da grande ocorrência de acidentes no trabalho. De acordo com a Lei Complementar no 150:

Acidente do trabalho é o que ocorre pelo exercício do trabalho a serviço de empresa ou de empregador doméstico ou pelo exercício do trabalho dos segurados provocando lesão corporal ou perturbação funcional que cause a morte ou a perda ou redução, permanente ou temporária, da capacidade para o trabalho. (BRASIL, 2015).

A construção civil apresenta altos índices de acidentes no trabalho, sendo um dos mais elevados no Brasil em comparação aos demais setores industriais, e para diminuir essa realidade é necessário que haja a aplicação nos canteiros de obras, das normas regulamentadoras de segurança do trabalho (SANTOS, 2018). Os índices de acidentes de trabalho no país são tão altos que chegam a 410 mil por ano, matam cerca de 3 mil pessoas e custam cerca de $\mathrm{R} \$ 32$ bilhões ao país (SILVA, 2011).

O Brasil se destaca no campo de acidentes na construção civil, em virtude do descumprimento das normas regulamentadoras e falta de medidas de segurança, sendo desconhecido por trabalhadores, ou que as vezes nunca tiveram algum tipo de treinamento, seja por desinteresse próprio ou negligência dos empregadores (GIZONI et al., 2018).

Quadro 1: Eventos do eSocial que contemplam informações de SST.

\begin{tabular}{|c|c|c|}
\hline Evento & Informação de SST & Requisito Legal \\
\hline S-1000 - Informações do Empregador/Contribuinte & FAP & Decreto no 3.048 \\
\hline S-1005 - Tabela de Estabelecimentos e Obras de Construção Civil & RAT & Decreto $n=3.048$ \\
\hline $\begin{array}{l}\text { S-1060 - Tabela de Ambientes de Trabalho; S-2240 - Condições } \\
\text { Ambientais do Trabalho - Fatores de Risco }\end{array}$ & Riscos ambientais & NR 9 - PPRA \\
\hline S-2220 - Comunicação do Acidente de Trabalho & $\begin{array}{l}\text { Comunicação de Acidente do } \\
\text { Trabalho (CAT) }\end{array}$ & Lei $\mathrm{n} 08.213$ \\
\hline S-2220 - Monitoramento da Saúde do Trabalhador & $\begin{array}{l}\text { Monitoramento de saúde do } \\
\text { trabalhador }\end{array}$ & NR 7 - PCMSO \\
\hline \multirow[t]{3}{*}{ S-2241 - Insalubridade, Periculosidade e Aposentadoria Especial } & Insalubridade & $\begin{array}{l}\mathrm{NR} \\
\text { Insalubridade }\end{array}$ \\
\hline & Periculosidade & $\begin{array}{lcl}\text { NR } & 16 & - \\
\text { Periculosidade } & \\
\end{array}$ \\
\hline & $\begin{array}{l}\text { Aposentadoria Especial (LTCAT e } \\
\text { PPP) }\end{array}$ & Decreto $n \circ 3.048$ \\
\hline
\end{tabular}

Estima-se que haja um acidente de trabalho a cada 48 segundos no Brasil, e a construção civil é o 40 setor econômico do país com o maior número de ocorrências, havendo aproximadamente 97 mil entre 2012 e 2018 (BUILDIN, 2019). Nesse sentido, o eSocial impacta diretamente na construção civil, e apesar da burocracia, é um impacto positivo, que obriga as empresas a se adequarem as normas de Saúde e Segurança no Trabalho, podendo, desse modo, diminuir os índices de acidentes no trabalho. Os eventos do eSocial associados à SST e à construção civil estão dispostos no quadro 1.

Apesar da obrigatoriedade e do disposto no eSocial, não há dados estatísticos que contenham a adequação de empresas da construção civil ao eSocial. Entretanto identifica-se que há muito a percorrer, visto que os índices de acidente de trabalho na indústria da construção civil são altos, e podem ser diminuídos com a adequação ao sistema do eSocial, onde a ausência deste fato resulta em multa à empresa. Nesse 
sentido, o eSocial impacta positivamente na construção civil, atuando na melhoria do trabalho, especialmente relacionado à Saúde e Segurança no trabalho.

Cabe ressaltar que somente a existência do eSocial não garante uma melhoria na questão de SST da construção civil, até mesmo porque, ANAMT (2019) afirma que há uma informalidade de em média 40\% na construção civil do Brasil. Desse modo, a aplicabilidade do eSocial não atinge estas. Porém o sistema promete uma melhor fiscalização, que anteriormente a ele era deficiente, além de muitas empresas não darem atenção aos programas e laudos exigidos pela legislação (BUILDIN, 2019). O eSocial altera significativa e positivamente a rotina dos profissionais de segurança e saúde ocupacional, bem como a indústria da construção civil, visto que ele não só altera a legislação da área, como também é uma forma de verificar a prática destas legislações nas empresas (BUILDIN, 2019).

Apesar do impacto positivo verificado para a construção, especialmente relacionado a SST, recentemente o governo federal anunciou sua extinção, prevista para janeiro de 2020, onde será substituído por outros dois sistemas, mais simples e com menos obrigatoriedade de informações, entre elas a questão da segurança no trabalho, onde há a exceção da não obrigatoriedade somente do registo de acidentes no trabalho, isso por conta das reclamações dos empregadores quanto a burocracia enfrentada pelo sistema.

Especialmente no ambiente da construção civil, essa mudança não torna-se positiva, visto que é uma área com um alto índice de negligência e acidentes no trabalho, e a existência de um sistema que obriga a realização de programas e entrega de documentos relativas à Saúde e Segurança no trabalho pode diminuir a problemática enfrentada.

\section{CONCLUSÕES}

Criado em 2014, o eSocial é um sistema que reúne informações e obrigações trabalhistas, fiscais e previdenciárias das empresas, que devem enviá-las ao governo via plataforma eletrônica de maneira unificada. Em virtude de apresentar em torno de 15 obrigações e inúmeros documentos, o eSocial tem sido debatido e questionado, visto que, ao obrigar o envio de tantos documentos, os empregadores enfrentam uma burocracia para se adequarem.

Apesar disso, no que se refere à construção civil, identifica-se que o eSocial impacta positivamente, em virtude da existência de obrigações relacionadas à Saúde e Segurança no Trabalho, que, por serem mais fiscalizadas, pode influenciar na diminuição do índice de acidentes no trabalho na construção civil, que é um dos mais altos do país.

A implantação do eSocial permite que haja uma maior e melhor verificação da Saúde e Segurança no trabalho, e apesar da existência da burocracia, verifica-se que esta pode ser uma ferramenta à melhoria das condições de trabalho na construção civil, diminuição da informalidade e consequentemente uma diminuição dos acidentes no trabalho.

Em virtude da resistência dos empregadores quanto ao sistema, o governo federal anunciou a extinção do eSocial, principalmente por conta da burocracia diante da vasta quantidade de documentos e obrigações. No lugar do eSocial, o governo pretende substituir por um sistema mais simples, que reúne 
menos obrigações, entre elas uma menor obrigação relacionada à Saúde e Segurança no Trabalho, passando a haver a obrigatoriedade somente do envio do Comunicado de Acidente do Trabalho - CAT.

Mesmo com a burocracia, o sistema pode influenciar na melhoria da construção civil, e sua inexistência, bem como a substituição por outro sistema com menos obrigações quanto à SST pode representar um atraso à segurança no trabalho na indústria da construção civil. Frente ao exposto, verificase uma necessidade de substituição do sistema por outro que, mesmo ao simplificar, reúna obrigações fundamentais à Saúde e Segurança no Trabalho, de modo a haver maior fiscalização e diminuir as irregularidades que causam um índice significativo de acidentes no trabalho.

\section{REFERÊNCIAS}

ANAMT. Associação Nacional de Medicina do Trabalho. Construção civil está entre os setores com maio risco de acidentes de trabalho. São Paulo: ANAMT, 2019.

BRASIL. Conheça o eSocial. Brasília: Governo Federal, 2017.

BRASIL. Lei Complementar N. 150, de 1ㅇ de Junho de 2015. Brasília: DUO, 2015.

BRASIL. Ministério do Trabalho e Emprego. NR 9: Programa de Prevenção de Riscos Ambientais. Brasília: MTE, 2017.

BRASIL. Ministério do Trabalho e Emprego. NR 17:

Ergonomia. Brasília: MTE, 2018.

BRASIL. O perfil profissiográfico previdenciário - PPP. Brasília: Ministério da Economia, 2014.

BRASIL. Publicado novo cronograma do eSocial. Brasília: Governo Federal, 2018.

BRASIL. Manual de Orientação do eSocial. Brasília, 2018

BRASIL. Ministério do Trabalho e Emprego. Portaria n. 3.214, de 08 jun. Aprova as Normas Regulamentadoras - NR - do Capítulo V, Título II, da Consolidação das Leis do Trabalho, relativas à Segurança e Medicina do Trabalho. Brasília: MTE, 1978.

BRASIL. Portal do Trabalho e Emprego. Cadastro Geral de Empregados e Desempregados - CAGED. Brasília: Portal do Trabalho e Emprego, 2014.

BUILDIN. eSocial: o que é e como ele afeta a construção civil. BUILDIN, 2019.

DONZELLI, O.; RODRIGUES, G. H.; SILVA, L. E. O.; ALFREDO, M. L.. E-SOCIAL: uma nova era nas relações entre empregadores, empregados e governos. Diálogos em Contabilidade: Teoria e Prática, v.1, n.1, 2013.

DUARTE, E. N.; RAMALHO, F. A.; AUTRAN, M. M. M.; PAIVA, E. B.; ARAÚJO, M. B. S.. Estratégias metodológicas adotadas nas pesquisas de iniciação científica premiadas na UFPB: em foco a Série 'Iniciados'. R. Eletr. Bibliotecon. Ci. Inf., Florianópolis, v.14, n.27, p.170-190, 2009.

SÃO PAULO. Federação das Indústrias do Estado De São Paulo. Cartilha: Segurança e Medicina do Trabalho. São Paulo, 2011.
GIZONI, M. S.; MARCO, G.. A importância da segurança no trabalho na construção civil: um estudo no município de Jaboticaba I - SP. São Paulo, 2018.

INSS. Instituto Nacional do Seguro Social. Comunicação de Acidente de Trabalho - CAT. Rio de Janeiro: INSS, 2018.

MOTERLE, Neodimar. A importância da segurança do trabalho na construção civil: um estudo de caso em um canteiro de obra na cidade de Pato branco - PR. Universidade Tecnológica Federal do Paraná, Pato Branco, 2014.

MORAES, L. D.. Análise da aplicabilidade das normas regulamentadoras em obras de pequeno porte da construção civil. Ijuí: Universidade Regional do Noroeste do Estado do Rio Grande do Sul, 2017

OCUPACIONAL. Medicina e Engenharia de Segurança do Trabalho. 6 documentos de SST necessários ao eSocial. 2019.

PRAÇA, F. S. G.. Metodologia da Pesquisa Científica: Organização estrutural e os desafios para redigir o trabalho de conclusão. Diálogos Acadêmicos, n.1, p.72-87, 2015.

PRODANOV, C. C.; FREITAS, E. C.. Metodologia do Trabalho Científico. 2 ed. Novo Hamburgo: Universidade Feevale, 2013.

SANTOS, P. V. S.. Aplicação de Normas Regulamentadoras de Segurança do Trabalho em Obras de Pequeno Porte. Uberlândia: Universidade Federal de Uberlândia, 2018.

SILVA, A. L. C.. A segurança do trabalho como uma ferramenta para a melhoria da qualidade. Santa Maria: Universidade Federal de Santa Maria, 2011

SILVA, A. M.; DIAS, I. F.; EVANGELISTA, W. L.. Análise de adequação de uma obra de pequeno porte, situada no oeste de Minas Gerais, com a Norma Regulamentadora 35 para trabalhos em altura: estudo de caso. In: ENCONTRO NACIONAL DE ENGENHARIA DE PRODUÇÃO, 25. Anais. Fortaleza: ENEGEP, 2015.

VIANA, A.; AMORIM, A.; MACHADO, N.. Seminário eSocial nos Sistemas Datamace. São Bernardo do Campo: Intersystem, 2014.

A CBPC - Companhia Brasileira de Produção Científica (CNPJ: 11.221.422/0001-03) detém os direitos materiais desta publicação. Os direitos referem-se à publicação do trabalho em qualquer parte do mundo, incluindo os direitos às renovações, expansões e disseminações da contribuição, bem como outros direitos subsidiários. Todos os trabalhos publicados eletronicamente poderão posteriormente ser publicados em coletâneas impressas sob coordenação da Sapientiae Publishing, da Companhia Brasileira de Produção Científica e seus parceiros autorizados. Os (as) autores (as) preservam os direitos autorais, mas não têm permissão para a publicação da contribuição em outro meio, impresso ou digital, em português ou em tradução. 